\title{
Efficacy of an lodophore Teat Disinfectant Against Staphylococcus aureus and Streptococcus agalactiae in Experimental Challenge
}

\author{
K. E. Leslie, ${ }^{1}$ C. S. Petersson, ${ }^{2}$ E. Vernooy, ${ }^{1}$ and A. Bashiri ${ }^{1}$ \\ ${ }^{1}$ Department of Population Medicine, \\ Ontario Veterinary College, University of Guelph, Canada N1G 2W1 \\ ${ }^{2}$ Department of Animal Sciences, Ohio State University, Columbus 43210
}

\section{ABSTRACT}

A $1.0 \%$ iodophore teat disinfectant (Full-Bac) was evaluated in comparison with a positive control (Bovadine), a commercially available $1.0 \%$ iodophore teat disinfectant. The study was conducted under conditions of experimental challenge, following the guidelines recommended by the National Mastitis Council. The test product and a positive control were compared in 41 cows, with 82 teats receiving each product at milking, during a 10 -wk study period. There were no differences between the test product and the positive control in new intramammary infections due to Staphylococcus aureus, which averaged $13.4 \%$ in each of the 2 treatment groups. Additionally, no statistical difference was seen between the test product and positive control in new intramammary infections by Streptococcus agalactiae, which averaged 8.5 and $6.1 \%$ for the Full-Bac and Bovadine groups, respectively. Teat skin and teat end condition scores were statistically evaluated at wk 1 , 5 , and 9 of the study, and no significant differences were observed between the treatment groups. The test teat disinfectant provided similar germicidal activity to that of the positive control teat disinfectant with no adverse effects on teat skin or teat end condition during the warm-season study period.

(Key words: iodophore, teat disinfectant, Staphylococcus aureus, Streptococcus agalactiae)

Abbreviation key: NMC = National Mastitis Council, TSB $=$ trypticase soy broth.

\section{INTRODUCTION}

It is widely accepted that the process of premilking udder preparation and postmilking teat disinfection are integral components of a successful mastitis control program (Radostits, 1994). With the large number of teat

Received June 15, 2004.

Accepted September 27, 2004.

Corresponding author: K. E. Leslie; e-mail: keleslie@ovc.uoguelph. ca. disinfectants available in the United States and Canada, dairy producers are faced with the decision as to which product has the most desirable combination of bacterial killing ability and promotion of teat skin health for their particular herd situation. Although this information is often difficult to obtain and interpret, the National Mastitis Council (NMC) publishes annually a bibliography of peer-reviewed research on the efficacy of commercially available teat disinfectants (NMC, 2002). Many of these products are iodophore solutions demonstrating excellent efficacy. However, it has been a significant challenge for teat disinfectant manufacturers to formulate products that not only achieve a high efficacy of bactericidal activity but also maintain the integrity of teat skin condition. Various types and concentrations of emollients are included in these products to ameliorate the impact of the germicide on teat skin. Generally, limited information is available on the effects of these products on teat skin health.

A 1.0\% iodophore postmilking teat disinfectant (FullBac, IBA, Inc., Millbury, MA) is produced, registered, and widely distributed in the United States. The purpose of the current study was to evaluate the efficacy of this teat disinfectant in preventing new IMI under conditions of experimental challenge with Staphylococcus aureus and Streptococcus agalactiae in dairy cows in Canada. In addition, teat skin and teat end health were examined. It has become a standard recommendation throughout the North American dairy industry to use postmilking teat disinfection; therefore, a positive control (Bovadine, West Agro, Inc., Kansas City, MO) was used in this study design, rather than compare the test disinfectant with a negative control.

\section{MATERIALS AND METHODS}

\section{Trial Facility and Animals}

Forty-one Holstein cows located at the Ponsonby Dairy Research Center, University of Guelph, were enrolled in the experiment. This facility is a 46-cow tiestall barn. The lactating cows are housed continuously, with daily exercise from 0800 to $1030 \mathrm{~h}$. The herd has a monthly herd average SCC linear score of 2.0 to 2.5, 
and annual milk production of approximately 10,000 $\mathrm{kg}$ per cow. The experiment was conducted from midMay through August 2003. All quarters of the trial cows were evaluated throughout the experimental period except those previously infected with the test organisms, and those with severe teat injury.

\section{Udder Preparation and Milking Management}

Trial cows were milked twice daily in a tie-stall dairy barn using a WestphaliaSurge (WestphaliaSurge Canada Co., Mississauga, Ontario, Canada) automatic take-off milking system. At every milking, each study cow was prepared for milking using the NMC-recommended approach for udder preparation. All teats were dipped in a commercially available, approved, $0.25 \%$ iodophore premilking teat disinfectant (Della-Pretech, DeLaval Co., Peterborough, Ontario, Canada) and wiped with a clean, dry, single-use cloth towel. The milking unit was attached within $60 \mathrm{~s}$ of preparation. During a 3-wk pretrial period, a commercially available postmilking iodophore teat disinfectant (Teat-Kote, WestphaliaSurge Canada Co.) was applied to all quarters of all experimental cows.

\section{Sample Collection and Bacteriological Culture of Milk}

During the trial period, quarter foremilk samples were aseptically collected each week at the Monday morning milking. Sampling and bacteriological procedures have been previously documented (Laboratory Handbook on Bovine Mastitis, 1999). All quarter samples were analyzed for SCC using a Bentley SomaCount 300 (Bentley Instruments Inc., Chaska, MN). For $3 \mathrm{wk}$ before the start of the experimental challenge, the bacteriological infection status of each quarter was established by weekly samples in addition to a duplicate quarter sample 1 wk before the challenge period commenced. Growth of 3 or more colony types in any sample was considered contamination, and the corresponding quarter was resampled to determine infection status. In addition, any quarter that was newly positive with a Strep. agalactiae or Staph. aureus isolate was resampled at the Thursday p.m. milking to confirm the new IMI. The SCC data were also used as a screening tool to identify quarters that were negative on bacteriological culture, but had elevated SCC greater than 300,000 cells $/ \mathrm{mL}$, so that they could be resampled and submitted for culture.

\section{Determination of a Positive Quarter}

A quarter was noted as positive for a new IMI, if any of the following criteria were met:
1. Signs of clinical mastitis were found, in which a duplicate milk sample was aseptically collected to confirm bacterial presence, before treatment.

2. Staph. aureus or Strep. agalactiae were cultured in moderate or large numbers (greater than or equal to $5.0 \times 10^{2} \mathrm{cfu} / \mathrm{mL}$ ) on 2 successive weeks

3. Staph. aureus, Strep. agalactiae, Staphylococcus spp., or Corynebacterium bovis were cultured in low numbers $\left(1.0 \times 10^{2}\right.$ to $\left.5.0 \times 10^{2} \mathrm{cfu} / \mathrm{mL}\right)$ on 3 successive samples.

If a quarter was classified as positive by any of the above criteria, it was treated with cephapirin sodium (CefaLak, Wyeth Laboratories, Guelph, Ontario, Canada), by intramammary infusion repeated once at 12 h. Early treatment of new IMI was intended to reduce the exposure to the challenge organism from the infected gland during the milking procedure, which would be beyond the intended experimental challenge. The rate of elimination of IMI was not examined in the current study.

\section{Preparation of Challenge Suspensions}

Staph. aureus challenge suspension. Three times weekly, Staph. aureus 29740 (American Type Culture Collection, Rockville, MD), was inoculated into a 6-mL tube of trypticase soy broth (TSB) and incubated at $37^{\circ} \mathrm{C}$ for 5 to $7 \mathrm{~h}$. The stock culture was streaked on blood agar to confirm sterility. Using TSB to dilute the culture, a concentration of approximately $5.0 \times 10^{7} \mathrm{cfu} /$ $\mathrm{mL}$ was achieved and confirmed by optical density spectrophotometry. At this time, $1 \mathrm{~mL}$ of the $6-\mathrm{mL}$ culture was aseptically transferred to $500 \mathrm{~mL}$ of TSB and incubated at $37^{\circ} \mathrm{C}$ for 16 to $18 \mathrm{~h}$. The bacterial cells were pelleted by centrifugation and washed twice with $0.1 \%$ proteose-peptone solution, and subsequently resuspended in proteose-peptone solution. The stock suspension was separated into aliquots and stored at $5^{\circ} \mathrm{C}$. A standard plate count was conducted on each aliquot (Laboratory Handbook on Bovine Mastitis, 1999).

Strep. agalactiae challenge suspension. Three times weekly, Strep. agalactiae 27956 (American Type Culture Collection), was inoculated into a $6-\mathrm{mL}$ tube of TSB and incubated at $37^{\circ} \mathrm{C}$ for $15 \mathrm{~h}$. Subsequently, 1 $\mathrm{mL}$ of the $6-\mathrm{mL}$ culture was aseptically transferred into $500 \mathrm{~mL}$ of TSB and incubated at $37^{\circ} \mathrm{C}$ for 6 to $7 \mathrm{~h}$. Using TSB to dilute the culture, a concentration of approximately $5.0 \times 10^{7} \mathrm{cfu} / \mathrm{mL}$ was achieved and confirmed by optical density spectrophotometry. The stock suspension was separated into aliquots and stored at $5^{\circ} \mathrm{C}$ until further use (Laboratory Handbook on Bovine Mastitis, 1999). 
Premilking challenge broth preparation. The challenge broths were removed from storage before the start of milking. The aliquots were warmed in a $37^{\circ} \mathrm{C}$ waterbath, and following a 30-min incubation, the broths containing Strep. agalactiae and Staph. aureus were combined.

\section{Challenge of Teats and Application of Teat Disinfectant}

Immediately following every milking, each teat was challenged by immersion ( $25 \mathrm{~mm}$ ) in a cup of prepared TSB suspension of Strep. agalactiae and Staph. aureus. After immersion, the bacterial suspension was left to air-dry on the teats (2 to $4 \mathrm{~min}$ ). The right front and left hind teats were dipped in the test teat disinfectant (Full-Bac), and the right hind and left front teats were dipped in the commercially available $1.0 \%$ iodophore teat dip (Bovadine), as a positive control.

\section{Evaluation of Teat Skin and Teat End Condition}

Teats were examined once weekly throughout the study for teat skin condition and teat end lesions. Teat skin condition was assessed using a previously published protocol (Goldberg et al., 1994). Teat-end conformation was evaluated following published guidelines (Goldberg et al., 1994). A pictorial chart to define this classification system was established using information from the Teat Club International (Mein et al., 2001). One research technician, who was previously trained in using the 5-point ordinal scales, performed all teat skin and teat end examinations.

\section{Statistical Methods}

The statistical procedures were conducted following previously described statistical procedures by Nickerson et al. (2004), as well as using a complex modeling system in SAS (SAS Institute, 2000) for new IMI. Teat end and teat skin score data were statistically evaluated in SAS.

Following recommendations by Nickerson et al. (2004) for new IMI, a Z-statistic was calculated based on the difference between IMI in quarters dipped with Full-Bac and those dipped with Bovadine. The equation used was as follows:

$$
\begin{gathered}
\mathrm{Z}=\left[\mathrm{x}_{1} / \mathrm{n}_{1}-\mathrm{x}_{2} / \mathrm{n}_{2}\right] /\left[\mathrm{p} \times(1-\mathrm{p}) / \mathrm{n}_{1}\right. \\
\left.+\mathrm{p} \times(1-\mathrm{p}) / \mathrm{n}_{2}\right]^{1 / 2}
\end{gathered}
$$

where $\mathrm{x}_{1}=$ number of new IMI in Bovadine-dipped quarters, $\mathrm{x}_{2}=$ number of new IMI in Full-Bac-dipped quarters, $\mathrm{n}_{1}=$ number of Bovadine-dipped quarters, $\mathrm{n}_{2}=$ number of Full-Bac-dipped quarters, and $\mathrm{p}=\left(\mathrm{x}_{1}\right.$ $\left.+\mathrm{x}_{2}\right) /\left(\mathrm{n}_{1}+\mathrm{n}_{2}\right)$.

The statistical significance was evaluated based on one-tailed standard normal tables. The percentage reduction of new IMI $=100\left[\left(\mathrm{x}_{1} / \mathrm{n}_{1}\right)-\left(\mathrm{x}_{2} / \mathrm{n}_{2}\right)\right] / \mathrm{x}_{1} / \mathrm{n}_{1}$.

For all statistical evaluations in SAS (SAS Institute, 2000), the Mantel-Haenszel procedure was used to carry out a preliminary quarter-level evaluation of the difference between the probability of a new IMI for a teat dipped with Full-Bac compared with one dipped with Bovadine. Although this procedure ignores the correlation of teats within cows, data with a $P$ value less than 0.20 were further analyzed to properly control for this effect. In this case, a statistical model using the GENMOD procedure in SAS (SAS Institute, 2000) was used to control for this correlation and, thus, better estimate the effect of treatment group.

To evaluate the effect of the disinfectants on teat skin and teat end condition, a summary statistic was calculated based on scores collected at wk 1, 5, and 9, accounting for repeated measures. This statistic was then formally tested using the mixed procedure in SAS (SAS Institute, 2000), controlling for the score at wk 0 and the random effect of cow.

\section{RESULTS AND DISCUSSION}

Infection data collected weekly over the trial period are shown in Table 1. Eleven new Staph. aureus infections were detected in each of the Full-Bac and Bovadine postmilking teat disinfected quarters. In total, 7 and 5 quarters became infected with Strep. agalactiae over the study for Full-Bac and Bovadine groups, respectively (Table 1). Using statistical procedures recommended by Nickerson et al. (2004), there was no difference in the Staph. aureus infection rate between the 2 treatment groups $(P=0.5)$. Similarly, the calculated Z-statistic for the rate of new Strep. agalactiae IMI indicated no difference $(P=0.7)$ between quarters dipped with Full-Bac and those dipped with Bovadine. Results from the Mantel-Haenszel procedure suggested that the odds of acquiring a new Staph. aureus infection over the study period was not different among the 2 treatment groups $(P=0.99)$. Likewise, the odds of gaining a new Strep. agalactiae IMI was not statistically different between quarters dipped with Full-Bac and those dipped with Bovadine $(P=0.73)$. The rates of new IMI were not significantly different between treatments using the Mantel-Haenszel procedure, therefore, no further statistical modeling was performed on the infection data.

The 2 analytical approaches provided similar results. However, it should be noted that if the Mantel-Haenszel procedure had found significant results, a more thor- 
Table 1. Summary of new IMI data for Full-Bac and Bovadine against Staphylococcus aureus and Streptococcus agalactiae under experimental challenge conditions in 41 dairy cows.

\begin{tabular}{|c|c|c|c|c|c|c|c|c|c|c|c|c|c|}
\hline \multirow{2}{*}{$\begin{array}{l}\text { Organism } \\
\text { and treatment }\end{array}$} & \multirow{2}{*}{$\begin{array}{l}\text { Quarters } \\
\text { eligible } \\
\text { for new IMI }\end{array}$} & \multicolumn{11}{|c|}{ New IMI by week } & \multirow{2}{*}{$\begin{array}{l}\text { Quarters } \\
\text { infected }(\%)\end{array}$} \\
\hline & & 1 & 2 & 3 & 4 & 5 & 6 & 7 & 8 & 9 & 10 & Total & \\
\hline \multicolumn{14}{|l|}{ Staph. aureus } \\
\hline Full-Bac & 82 & 0 & 1 & 1 & 3 & 1 & 2 & 3 & 0 & 0 & 0 & 11 & $13.4^{\mathrm{a}}$ \\
\hline Bovadine & 82 & 0 & 0 & 2 & 1 & 1 & 2 & 1 & 1 & 2 & 1 & 11 & $13.4^{\mathrm{a}}$ \\
\hline \multicolumn{14}{|l|}{ Strep. agalactiae } \\
\hline Full-Bac & 82 & 0 & 2 & 1 & 0 & 0 & 0 & 0 & 1 & 1 & 2 & 7 & $8.5^{\mathrm{b}}$ \\
\hline Bovadine & 82 & 0 & 0 & 0 & 0 & 0 & 0 & 0 & 1 & 2 & 2 & 5 & $6.1^{\mathrm{b}}$ \\
\hline
\end{tabular}

${ }^{\text {a}}$ Not significantly different at $P \leq 0.05$.

${ }^{b}$ Not significantly different at $P \leq 0.05$.

ough statistical analysis allowing for the proper control of potentially confounding variables would have been warranted. This is of particular importance for studies using a negative control group, where the difference in IMI rate is much more pronounced. Although the Zstatistic is a widely used and accepted method, the use of more advanced approaches to modeling the data may provide more appropriate analysis of the results.

The average teat skin and teat end scores throughout the study are shown in Table 2. Although some slight differences were seen among the weeks, the mean teat skin score over the 9 -wk period was 2.6 for the FullBac and Bovadine teat disinfection groups. Similarly, the teat end condition averaged 2.1 in both treatment groups. Teat skin and teat end condition scores were recorded once weekly. The statistical power of these data may detect very minor changes in teat end and teat skin condition scores as being statistically significant, which are probably not biologically important to functionality or health. In an effort to moderate the power
( $\beta=0.90$ ), only data from the beginning (wk 1 ), middle (wk 5), and end (wk 9) of the study were used for statistical analyses. Using the scores from wk 1, 5, and 9, and treating the effects of each cow as random, no difference was seen in the summary statistic for teat end condition between treatment groups $(P=0.91)$. Similarly, the teat skin scores for each treatment group resulted in a summary statistic that was not significantly different $(P=0.38)$. Therefore, the emollient formulation in FullBac resulted in similar teat health to that in Bovadine for the duration of the 9-wk study. However, it is emphasized that this study was conducted during the early summer months, a time when the teat condition is normally less of a concern than during conditions of more extreme temperature change in the late fall and winter months. To determine if an improvement in teat condition can be achieved with the use of one product over the other, it may be useful to conduct an experiment over a more extended period of time that would include

Table 2. Average teat skin and teat end scores for quarters dipped with Full-Bac and those dipped with Bovadine recorded once weekly during a 9-wk experimental challenge study with Staphylococcus aureus and Streptococcus agalactiae on 41 dairy cows, using an ordinal scale (1 to 5).

\begin{tabular}{|c|c|c|c|c|c|c|c|c|c|c|}
\hline \multirow{2}{*}{$\begin{array}{l}\text { Origin } \\
\text { and } \\
\text { treatment }\end{array}$} & \multicolumn{9}{|c|}{ Week } & \multirow[b]{2}{*}{ Average } \\
\hline & 1 & 2 & 3 & 4 & 5 & 6 & 7 & 8 & 9 & \\
\hline \multicolumn{11}{|l|}{ Teat skin ${ }^{1}$} \\
\hline Full-Bac & 2.1 & 1.9 & 2.1 & 2.1 & 2.1 & 2.1 & 2.1 & 2.2 & 2.2 & 2.1 \\
\hline Bovadine & 2.1 & 2.0 & 2.1 & 2.1 & 2.0 & 2.1 & 2.0 & 2.1 & 2.1 & 2.1 \\
\hline \multicolumn{11}{|l|}{ Teat end ${ }^{2}$} \\
\hline Full-Bac & 2.6 & 2.6 & 2.8 & 2.5 & 2.6 & 2.5 & 2.4 & 2.5 & 2.6 & 2.6 \\
\hline Bovadine & 2.6 & 2.7 & 2.8 & 2.5 & 2.6 & 2.5 & 2.5 & 2.6 & 2.7 & 2.6 \\
\hline
\end{tabular}

${ }^{1}$ Teat skin scores: 1 = teat skin is smooth and free from scales, cracks, or chapping; $2=$ teat skin shows some evidence of scaling and dryness; 3 = teat skin is chapped and some small warts may be present; $4=$ teat skin is chapped and cracked; redness indicates inflammation and numerous warts may be present; $5=$ teat skin is severely damaged and ulcerative with scabs or open lesions, large or numerous warts may be present.

${ }^{2}$ Teat end scores: 1 = teat end sphincter is smooth with no evidence of irritation; $2=$ teat end sphincter has a raised but smooth ring; $3=$ teat end sphincter is roughened with slight cracks, but no redness is present; 4 = teat end sphincter is inverted with severe radial cracking, giving a "flowered" appearance, and may have old but healing cracks; 5 = teat end sphincter is severely damaged and ulcerative with scabs or open lesions, large or numerous warts present that interfere with teat end function. 
periods when low temperatures and wind-chill are more prominent factors.

\section{CONCLUSIONS}

It is concluded that the efficacy of Full-Bac and Bovadine for the prevention of new Staph. aureus and Strep. agalactiae IMI under experimental challenge conditions did not differ significantly. These findings suggest that the test teat disinfectant (Full-Bac) provided similar germicidal activity to that of the positive control (Bovadine) teat disinfectant. In addition, the teat skin and teat end condition was not significantly different between the 2 treatment groups over the study period.

\section{ACKNOWLEDGMENTS}

The investigators gratefully acknowledge the financial and scientific support of IBA Incorporated, Millbury, MA. The efforts of the manager and staff of the University of Guelph Ponsonby Dairy Research Station are appreciated.

\section{REFERENCES}

Goldberg, J. J., A. J. Bramley, P. A. Drechsler, T. C. Hemling, J. L. Jones, J. K. O’Neil, M. Winicov, and J. W. Pankey. 1994. Evaluation of teat conditioning qualities of post-milking teat dips. Page 334 in Natl. Mastitis Counc. Mtg. Proc., Orlando, FL. Natl. Mastitis Counc., Inc., Arlington, VA.

Laboratory Handbook on Bovine Mastitis. National Mastitis Council, Inc. 1999. Natl. Mastitis Counc., Inc., Madison, WI.

Mein, G. A., F. Neijenhuis, W. F. Morgan, D. J. Reinemann, J. E. Hillerton, J. R. Baines, I. Ohnstad, M. D. Rasmussen, L. Timms, J. S. Britt, R. Farnsworth, N. Cook, and T. Hemling. 2001. Evaluation of bovine teat condition in commercial dairy herds: noninfectious factors. Pages 347-351 in Int. Symp. on Mastitis and Milk Quality Mtg. Proc., Vancouver, BC, Canada. Natl. Mastitis Counc., Inc., Madison, WI.

National Mastitis Council. 2002. Summary of peer-reviewed publications on efficacy of pre-milking and post-milking teat disinfectants published since 1980. Pages 245-258 in Natl. Mastitis Counc. Mtg. Proc., Orlando, FL. Natl. Mastitis Counc., Inc., Madison, WI.

Nickerson, S. C., A. Saxon, L. K. Fox, T. Hemling, J. S. Hogan, J. Morelli, S. P. Oliver, W. E. Owens, M. Pawlak, and L. G. Petersson. 2004. Efficacy evaluation of postmilking teat germicides: Updated protocols. Pages 379-398 in Proceedings of the National Mastitis Council Annu. Mtg., Charlotte, NC. Natl. Mastitis Counc., Madison, WI.

Radostits, O. M. 1994. Pages 220-371 in Herd Health: Food Animal Production Medicine. 3rd ed. W. B. Saunders, Philadelphia, PA. SAS Institute. 2000. User's Guide: Statistics. Version 8.2. SAS Inst., Inc., Cary, NC. 